\title{
Cellular Mechanisms of MOF During Severe Sepsis and Septic Shock
}

\author{
Barbara Assenzio and Erica L. Martin-Conte \\ University of Turin \\ Italy
}

\section{Introduction}

Severe sepsis and septic shock continue to plague intensive care units, leading to significant morbidity and mortality (Vincent et al., 2007). During the pathogenesis of sepsis, patients often develop multiple organ failure (MOF), which is believed to be the main cause of death (Vincent et al., 2007), indicating that either treatment or prevention of MOF could have profound therapeutic implications. However, despite extensive research in this field, the mechanisms and cellular pathophysiology involved in the transition of sepsis to MOF remain unclear, likely due to their immense complexity and cross-talk between signalling pathways.

This chapter aims to highlight the current knowledge regarding the pathophysiology of sepsis-induced organ dysfunction and failure, specifically outlining the current state of knowledge regarding septic-induced dysfunction of the lung, liver, kidney, cardiovascular system and brain For each of these organ systems, we will identify the major cell types prone to damage and briefly describe the key molecular pathways thought to contribute to this phenomenon, thereby ascertaining possible novel therapeutic targets.

\section{LPS-TLR4 signalling pathway}

Septic shock is initiated by a complex set of pathophysiological responses to the invasion of foreign microbial pathogens in the body. The most common organisms isolated during septic shock are gram-negative bacteria, which contain large quantities of lipopolysaccharide (LPS) in their cellular membranes (Legrand et al., 2010). LPS and its interaction with the Toll-like receptor 4 (TLR-4), is believed to be the major trigger of the septic signalling cascade (Salomao et al., 2008). To briefly describe this important cellular interaction; LPS, in association with LPS-binding protein and the receptor CD14, forms a complex with TLR-4 (Salomao et al., 2008). This complex then recruits the Toll-IL-1 resistance (TIR)-domain-containing adaptor molecules to the cytosolic surface of TLR-4. The four known adaptor proteins include 1) myeloid differentiation factor 88 (MyD88), 2) MyD88 adaptor-like protein, 3) TIR-domain-containing adaptor molecule 1 (TRIF) and 4) TRIF-related adaptor molecule. Depending on which of these adaptor molecules are involved, LPS-TLR4 signalling can be categorized as either early MyD88-dependent responses or delayed MyD88-independent responses. Of these, the more commonly characterized MyD88-dependent pathway initiates the phosphorylation of various 
signalling kinases, induces the nuclear translocation of the transcription factor NF- $\mathrm{BB}$ and ultimately the up-regulation of inflammatory cytokines and mediators (Salomao et al., 2008; Baumgarten et al., 2006). In general, these cytokines (including tumor necrosis factor (TNF), interlukin-1 (IL-1), IL-6, IL-8) and inflammatory mediators (coagulation factors, complement, nitric oxide, ROS) can induce cellular dysfunction and apoptosis resulting in tissue injury and organ failure (Baumgarten et al., 2006; Rittirsch et al., 2008; Cunningham et al., 2004). Other micro-organisms, such as gram-positive bacteria, viruses and fungi, can also induce a strong inflammatory reaction; however, this is often induced through modified signalling mechanisms, such as the TLR-2 pathway (Salomao et al., 2008; Legrand et al., 2010).

This chapter will attempt to review the mechanisms and pathophysiology involved in the cellular injury and tissue dysfunction of the main organ systems affected during severe sepsis and septic shock. Moreover, this manuscript will highlight target molecules that are unique or of particular importance to the development of organ injury, to outline current evidence regarding the development and application of novel therapeutic targets in the clinical treatment of septic shock.

\section{Lung}

\subsection{Pathophysiology}

The lung is often the first organ to undergo dysfunction during sepsis, due to its early involvement in the inflammatory process, leading to the culmination of acute lung injury (ALI) or acute respiratory distress syndrome (ARDS) (Bellingan, 2002). The development of ARDS significantly worsens patient outcome, with associated mortality rate rising to between $30-60 \%$ (Ware \& Matthay, 2000). This process is believed to be initiated by activation of resident alveolar macrophages, which produce inflammatory mediators causing the activated leukocytes of the circulation to be recruited towards the lung (Abraham \& Singer, 2007). This army of phagocytes invades the pulmonary interstitium causing the breakdown of endothelial and epithelial barriers thereby leading to significant tissue edema (Bhatia \& Moochhala, 2004). This plague of leukocytes both responds and contributes to inflammation by producing various cytokines, reactive oxygen species (ROS), protein kinases, and transcription factors which perpetuate the influx of more leukocytes, causes direct injury to lung tissue and provokes cellular apoptosis (Bhatia \& Moochhala, 2004; Abraham \& Singer, 2007; Marshall, 2001). The consequence of these cellular alterations is the formation of hyaline membranes, fibrin deposition, surfactant alterations and impaired gas exchange, leading to the therapeutic requirement of mechanical ventilation support (Abraham \& Singer, 2007). As if this damage was not enough, mechanical ventilation itself, while being a necessary life-saving intervention, can act as a "secondary hit", causing additional injury known as ventilator-induced lung injury (VILI), which occurs due to excessive stretch of pulmonary alveoli (Vlahakis \& Hubmayr, 2005).

\subsection{Major cell types involved}

The major cell types involved include alveolar macrophages that initiate the pulmonary inflammatory response, leukocytes, including neutrophils and monocytes that are recruited to the lung, pulmonary endothelial and epithelial cells (both type I and type II) that regulate the barriers of the lung, and fibroblasts that are involved in injury-repair processes. 


\subsection{Key molecular pathways and possible therapeutic targets \\ 3.3.1 TLR-4 and inflammation}

As described above, TLR-4 signalling plays role in the septic response of most organs, but has been intensely studied in the specific context of ALI and ARDS (Bhatia \& Moochhala, 2004). TLR-4 signalling is known to activate either directly or indirectly through MyD88 the nuclear translocation of $\mathrm{NF \kappa B}$, which in turn stimulates the production of a vast array of inflammatory proteases and cytokines (Salomao et al., 2008). The central role of TLR in the septic response is further supported by genetic studies that demonstrate that polymorphic variations in TLR-4 can predispose patients to gram-negative bacteremia and septic shock (Agnese et al., 2002; Lorenz et al., 2002). The importance of downstream NFkB signalling has also been emphasized by the clinical observation that in neutrophils from patients with septic-induced ARDS the amount of NFKB activity is associated with fewer ventilator-free days (Yang et al., 2003) and decreased survival (Bohrer et al., 1997). Of the cytokines stimulated by TLR-4, TNF $\alpha$ and IL-1 $\beta$ are believed to be the major mediators of septic shock (Bhatia \& Moochhala, 2004). Both of these mediators are release in the very early stages of the inflammatory response, appearing within 30-90 minutes, and in turn activate a second level of the inflammatory cascade including other cytokines, lipid mediators and reactive oxygen species (Bhatia \& Moochhala, 2004). The specific role TNF $\alpha$ is highlighted by several studies which report that the ratio of TNF $\alpha$ to its receptor TNFR is significantly correlated with increased organ dysfunction and patient mortality (Pellegrini et al., 1996), and genetic polymorphisms in TNF both increase the amount of circulating TNF and worsen patient outcome (Stuber et al., 1996). Furthermore, there is currently a prospective, randomized, double-blind, multi-center, phase II clinical trial underway testing the efficacy of an antiTNF antibody (ALT-836) versus placebo in the prevention of septic-induced ALI/ARDS, with the primary outcomes being patient safety and ventilator-free days (clinicaltrials.gov NCT00879606). In addition to TNF $\alpha$ and IL-1 $\beta$, other cytokines and inflammatory mediators thought to play an important role in the pathogenesis of ARDS during septic shock include, but is not limited to, IL-6, IL-8, IL-10, IL-4, granulocyte colony-stimulating factor (G-CSF), inter-cellular adhesion molecule-1 (ICAM-1), complement component 5a (C5a) and various pro-coagulation molecules (Bhatia \& Moochhala, 2004; Bozza et al., 2007).

\subsubsection{The RAGE axis}

The receptor for advanced glycation end-products, or RAGE, is an inflammation perpetuating receptor with a diverse range of ligands, for which there is compelling evidence for its role in the development of systemic inflammation and ALI (Creagh-Brown et al., 2010). While RAGE is expressed at low levels in all cells, it has a uniquely high constitutive expression in the lung (Buckley \& Ehrhardt, 2010), which is further upregulated upon activation by its various ligands (Schmidt et al., 2000), including S100 proteins, high mobility group proteins and advanced glycation end-products. RAGE signalling has been described to involve NFKB, mitogen-activated protein kinases (MAPK), and phosphoinositide 3-kinases (PI3K) which in turn lead to increased production of inflammatory cytokines, proteases and oxidative stress (Creagh-Brown et al., 2010). Interestingly, genetic ablation or inhibition of RAGE has consistently shown to increase survival in several different animal models of severe sepsis and septic shock (Creagh-Brown et al., 2010), and has additionally been reported to decrease septic-induced lung injury even when blocked therapeutically up to $24 \mathrm{hrs}$ following the initiation of sepsis (Lutterloh et al., 
2007). In accordance, similar results are found regarding the RAGE ligand HMGB1, which is known to be a late mediator of sepsis released from injured and stressed cells (CreaghBrown et al., 2010). Similar to RAGE, inhibition of HMGB1 during sepsis has also been shown to decrease lung injury and improve survival (Sawa et al., 2006; Yang et al., 2008). In clinical studies, patients with ALI have been observed to have increased soluble RAGE (sRAGE) in bronchioalveolar lavage fluid (BAL), and sRAGE levels correlated in severity of illness, ALI and mortality (Calfee et al., 2008; Uchida et al., 2006). Furthermore, ALI patients also display increased levels of various RAGE ligands (Creagh-Brown et al., 2010). While the benefits of RAGE inhibition have not been tested in the context of septic shock or ARDS, it is currently being assessed in the treatment of Alzheimer's dementia (clinicaltrials.gov NCT00566397), which will provide valuable information regarding patient safety, which could assist in establishing future trails in the treatment of septic shock.

\subsubsection{Phosphoinositide 3-kinase gamma (PI3K $\gamma)$}

Various phosphorylation molecules have been shown to significantly contribute to lung injury during the pathogenesis of severe sepsis and septic shock. In 2001, Yum et al. first showed that specific loss of PI3K $\gamma$ induced protection against acute lung injury in an experimental model of LPS-induced sepsis (Yum et al., 2001). While this paper was later challenged by a contradictory study using a model of E.coli (Ong et al., 2005), these original findings have since been confirmed in an extensive study by Martin et al. (Martin et al., 2010). In this most recent study, both the genetic and pharmacological blockade of the kinase activity of PI3K $\gamma$ activity was shown to decrease lung inflammation, edema, and neutrophil invasion, and improve survival, even when pharmacological inhibition occurred up to 9 hours following the initiation of sepsis (Martin et al., 2010). Furthermore, this study demonstrated that these effects are likely due to decreased GRK2 phosphorylation and consequent maintenance of the receptor CXCR2 expression on neutrophils (Martin et al., 2010). This, in turn, improves neutrophil recruitment to the origin of infection during severe sepsis, allowing for improved bacterial control and decreased decompartmentalization of the infection into the systemic circulation (Martin et al., 2010). Moreover, PI3K $\gamma$ is known to lie upstream to other phosphorylation molecules including Akt (or PKB), MAP kinases and $\mathrm{NF \kappa B}$, which have each been identified as contributors to lung injury during severe sepsis and septic shock (Martin \& Ranieri, 2011).

\subsubsection{Fas}

Apoptosis, or programmed-cell death, occurs frequently in tissues under stress or injury as an attempt to limit necrosis; however in several disease pathologies including severe sepsis and septic shock, high levels of apoptosis can in itself be destructive (Wheeler, 2009). Apoptosis occurs through two distinct pathways; the intrinsic pathway involving mitochondrial signalling and the extrinsic pathway involving activation of cell surface death receptors (Wheeler, 2009). Fas is a type of death receptor for which there is compelling evidence for its fundamental role in pulmonary epithelial cells in the pathogenesis of septicinduced ALI and ARDS (Chopra et al., 2009). In patients with ALI or ARDS, high levels of soluble Fas and its ligand (FasL) in BAL fluid correlate with increased mortality (Albertine et al., 2002; Matute-Bello et al., 1999). This role is supported by the fact that mice deficient in either Fas or FasL are protected from lung injury (Neff et al., 2005). More recent studies have shown that silencing the expression of Fas or the related Fas-associated death domain 
(FADD) decreases lung apoptosis, injury and inflammation during sepsis (Perl et al., 2007; Matsuda et al., 2009). In addition this apoptotic pathway appears to be particularly dominant in this context, since silencing Fas, but not caspase- 8 of the intrinsic pathway, in lung epithelial cells ameliorated pulmonary apoptosis, inflammation and neutrophil influx in a model of hemorrhage shock and sepsis (Perl et al., 2005). Moreover, in pulmonary epithelium, Fas can directly induce the production and release of inflammatory mediators, which further perpetuates the cycle of destruction (Perl et al., 2007). Together these data make Fas a potential therapeutic target that should be further explored in future studies.

\subsubsection{Activated protein C (APC)}

Activated protein C (APC) is a plasma serum protease that plays a central role in endogenous anti-coagulation. The PROWESS study, published in 2001, demonstrated the clinical significance of this molecule in the pathogenesis of sepsis, since administration of human recombinant APC (rhAPC) was found to significantly reduce mortality in patients with severe sepsis (Bernard et al., 2001). The specific role of APC in septic-induced ALI or ARDS has also been explored since protein $C$ levels are documented to be decreased in ALI patients of both septic or non-septic origin, and that these reduced levels correlated with poor clinical outcome (Shorr et al., 2006; Matthay \& Ware, 2004). These clinical finding are supported by studies in sheep, demonstrating that treatment with rhAPC in endotoxin or peritoneal-induced sepsis can reduce lung edema and injury (Waerhaug et al., 2008; Wang et al., 2007). Although APC is known for its anti-coagulative effects, these alone can not account for the improved clinical outcome in septic patients, since targeting of either activated factor $X$, anti-thrombin or tissue factor inhibitors has failed to produce a comparative protection (Sarangi et al., 2010). As such, APC has also been described to induce several cytoprotective effects which likely contribute to its success in the treatment of sepsis. These mechanisms include: 1) decreasing apoptosis (Mosnier et al., 2007), 2) the ability to bind to nuclear ribonucleoproteins, thereby facilitating the clearance of nuclear material from injured and necrotic tissue (Jean-Baptiste, 2007), 3) mediating the protection of the endothelial barrier, which prevents the destructive massive infiltration of neutrophils (Rittirsch et al., 2008), 4) a number anti-inflammatory effects including the decrease of tissue factor and thrombin, which in turn can induce inflammation, and the blockade of NFkB, which subsequently decreases the direct up-regulation of cytokines (Sarangi et al., 2010). Future studies, including the current multi-centered, phase III clinical trial PROWESS SHOCK (clinicaltrials.gov NCT00604214), are likely to further investigate and clarify the various mechanisms involved in APC-induced ALI protection during sepsis.

\section{Liver}

\subsection{Pathophysiology}

The liver is the largest solid organ in the body, comprising $2-5 \%$ of the body weight of a normal adult. Its function is believed to play a major role in the development of multiple organ dysfunction syndrome due to its central control of metabolism and host defence mechanisms (Van Amersfoort et al., 2003); however it remains one of the most poorly characterized and understood organs involved in MOF. During septic shock the evolution of liver dysfunction can be divided in two phases. The early phase involves hepatocyte dysfunction induced by gut-derived norepinephrine, which activates $\alpha_{2}$-adrenoceptors, which stimulate Kupffer cells to enhance TNF- $\alpha$ release and depresses hepatocellular 
function in the absence of hepatic blood flow alterations (Yang et al., 2001). In contrast, the late phase results mainly from a decreased hepatic perfusion, which mechanistically has been linked with increased coagulation, inflammation and derangement of endothelial nitric oxide synthase (eNOS) signalling (Dhainaut et al., 2001; Mookerjee, 2011). In addition, Kupffer cells can play either a protective or destructive role in the septic response of the liver, in that they are important in the removal and detoxification of LPS, while they can also initiate an exaggerated inflammatory response which can cause further liver damage (Van Amersfoort et al., 2003). Specifically, excessive inflammatory mediators can induce endothelial damage causing barrier breakdown and permeability, and are thought to be the driving force behind increased intra-hepatic resistance (Dhainaut et al., 2001; Mookerjee, 2011). Furthermore, the development of hyperlipidemia in response to sepsis is believed to result from pathomorphological changes in sinusoidal endothelial cells (Cheluvappa et al., 2010). Moreover, recent animal studies have shown that liver injury and dysfunction during sepsis is associated with G1 cell cycle arrest of hepatocytes and that hepatic function recovery was furthermore accompanied by cell cycle progression (Yang et al., 2011). Overall, these cellular defects result in loss of metabolic function, hypoglycaemia, lactic acidosis and coagulopathy.

\subsection{Major cell types involved}

In the pathogenesis of septic-induced liver dysfunction several hepatic cell types have been shown to be involved. This includes the parenchymal cells or hepatocytes, which are the main structural cell type of the liver comprising about $60 \%$ of the liver. These cells are highly metabolically active regulating lipids, bile and glucose. In addition, endothelial cells, which line the many sinusoids, and Kupffer cells, which are the resident macrophages of the liver, are also known to be significantly involved in the progression of sepsis to MOF. Moreover, circulating neutrophils which are recruited to the liver due to the high production of inflammatory cytokines have also been shown to contribute to this pathology.

\subsection{Key molecular pathways and possible therapeutic targets \\ 4.3.1 Tumor necrosis factor}

While several inflammatory cytokines including IL-6 and IL-1 $\beta$ have been implicated in the pathogenesis of liver dysfunction during sepsis, there is overwhelming evidence for a predominant role of TNF- $\alpha$ in this process. TNF- $\alpha$ is produced in large quantities primarily by Kupffer cells during the very early phase of hepatocyte dysfunction, following $\alpha_{2}-$ adrenergic stimulation (Yang et al., 2001; Fong et al., 1990). These high levels of TNF- $\alpha$ are shown to induce a variety of effects including the production of acute phase proteins (APPs), which serve several physiological function of the immune response (Dhainaut et al., 2001). However, the high up-regulation of APPs has also been associated with the development of liver failure (Ananian et al., 2005). Both TNF- $\alpha$ and their induced APPs also enhance pro-coagulant activity of vascular endothelial cells (Bevilacqua et al., 1986), which in turn can decrease hepatic perfusion, leading to further injury, as well as further ignite the inflammatory cascade (Dhainaut et al., 2001). TNF- $\alpha$ also up-regulates the expression adhesion molecules facilitating an excessive recruitment of activated neutrophils, which through the production of destructive proteases and reactive oxygen species, amplifies the damage to hepatocytes and endothelial cells (Zhang et al., 1994; Malmros et al., 1994; Holman, Jr. \& Saba, 1988). 


\subsubsection{Thrombin/ anti-thrombin}

Coagulation, resulting from an imbalance between pro- and anti-thrombin in the liver, occurs within the early phases of sepsis and significantly contributes to patient mortality (Stearns-Kurosawa et al., 2011). In vivo animal studies have described that microthrombi develop in the hepatic microcirculation with five minutes of an endotoxin challenge (Asaka et al., 1996). Furthermore, if the endotoxin dose is sublethal, clot lysis occurs with a few hours and hepatic architecture is conserved, while if endotoxin exposure continues, there develops clot accumulation, hypoperfusion, coagulation necrosis and irreversible tissue injury (Asaka et al., 1996). In addition, many studies have demonstrated that coagulation can further activate the inflammatory cascade, and visa versa, leading to a positive-feedback interaction (StearnsKurosawa et al., 2011; Jagneaux et al., 2004; Dhainaut et al., 2001). Novel treatments targeting thrombin activity during sepsis has been shown to decrease serum bilirubin concentrations and prevent liver dysfunction (Nitescu et al., 2007; Inthorn et al., 1997); however its overall role in reducing septic mortality is still unclear (Wiedermann et al., 2006).

\subsubsection{Activated protein C (APC)}

Protein $\mathrm{C}$ is a zymogenic protein that is produced by the liver and later converted to the active serine proteinase, which degrades Factors Va and VIIIa of the coagulation cascade, thereby preventing excessive thrombin formation (Stearns-Kurosawa et al., 2011). During septic shock the synthesis of protein $C$ is significantly decreased due to hepatocyte dysfunction, which correlates with disease severity and poor patient prognosis (StearnsKurosawa et al., 2011). Apart from coagulation, APC has also been described to possess several cytoprotective effects including the ability to degrade damaging histones, antiinflammatory and anti-apoptotic activities and stabilization of endothelial barriers (Mosnier et al., 2007; Xu et al., 2009), which can each limit hepatic injury. In addition, treatment of septic patients with rhAPC can decrease liver dysfunction (Rinaldi et al., 2008), which in animal experiments has been shown to result from an ability of APC to attenuate leukocyte trafficking into the liver (Huynh et al., 2010).

\subsubsection{Complement system}

The complement system is a family of proteins produced mainly by the liver that at normal physiological levels assist phagocytic cell to clear invading pathogens (Ward \& Gao, 2009). However, during the pathogenesis of sepsis, the liver is stimulated to produce exceedingly high concentrations of complement factors, such as $\mathrm{C} 5 \mathrm{a}$, which in large quantities produce an array of detrimental effects (Ward \& Gao, 2009). These include the up-regulation of tissue factor leading to intensified coagulation, the induction of neutrophil paralysis that causes uncontrolled bacterial expansion, as well as increased inflammation and apoptosis, which all contribute to the development of MOF (Ward \& Gao, 2009). Furthermore, several organs, including the liver, increase the expression of the C5a receptor during sepsis, which if blocked by an antagonist has been shown to improve organ function and survival in various animal models (Guo \& Ward, 2006; Riedemann et al., 2002).

\section{Kidney}

\subsection{Pathophysiology}

Acute kidney injury (AKI), a complex disorder with clinical manifestations ranging from a minimal elevation in serum creatinine to anuric renal failure, and is a frequent and serious 
complication of sepsis in intensive care unit (ICU) patients (Lafrance \& Miller, 2010). Moreover, there is strong evidence that septic AKI, accounting for $50 \%$ or more of cases of AKI in ICUs, is associated with a very high mortality (Uchino et al., 2005). Despite extensive research and progress in several other fields, the incidence, as well as mortality of septic AKI, remains at unacceptable levels (Silvester et al., 2001). A possible explanation of failure in the treatment of septic AKI is the relative lack of histopathologic information and reliance on creatinine measurements for assessment of kidney function, both leading to an incomplete understanding of the pathogenesis of this condition (Wan et al., 2008). AKI has been traditionally thought to be induced by ischemia secondary to decreased cardiac output and hypotension, which in turn leads to renal vasoconstriction and exacerbate the ischemia. Most of our understanding regarding renal blood flow (RBF) during sepsis relies on animal models. Across these studies, the heterogeneous nature of animals used, methods of inducing sepsis, and observed changes in RBF that vary from unchanged, decreased, and markedly increased all translate to uncertainty regarding their applicability to humans (Langenberg et al., 2007; Bagshaw et al., 2007). The characteristic pattern of RBF in human sepsis is for the most part largely unknown because RBF cannot be measured continuously in humans, and even its intermittent measurement requires a high level of invasiveness (Langenberg et al., 2007; Licari et al., 2007). Only a small study with limited patients has measured RBF in patients with sepsis, and reported that RBF was either preserved or increased in these patients (Bradley et al., 1976) However, recent findings suggest that, although hemodynamic factors may play a role in the loss of glomerular filtration, they do not necessary involve renal ischemia. In addition, other mechanisms including immunologic, toxic and inflammatory factors seem to affect the microvasculature and the tubular cell function. Apoptosis induced by LPS or cytokines, for instance, has emerged as a possible cause of loss of function of both endothelial and epithelial tubular cells (Humphrey et al., 1991).

\subsection{Major cell types involved}

The major cell types involved in the development of septic AKI includes all the cells forming the functional unit of the nephron. Tubular epithelium, podocytes, endothelium, and mesangial cells have been found to be directly affected by exposure to LPS, as well as susceptible to the inflammatory state induced by sustained bacterial infection.

\subsection{Key molecular pathways and possible therapeutic targets \\ 5.3.1 Apoptosis pathway}

LPS can directly cause apoptosis of tubular cells through the Fas-mediated and caspasemediated pathways and increased plasma levels of soluble Fas has been described in septic patients (Jo et al., 2002). Additionally, experimental models of sepsis have shown that increased caspase activation is associated with the presence of AKI (Guo et al., 2004). In recent studies it has been demonstrated that plasma of septic patients can induce apoptosis of tubular cells and that the amount of this cell death correlates with the extent of proteinuria, which in turn is related with the severity of the septic process, with the impairment of renal function and with patient outcome (Cantaluppi et al., 2008). The extrinsic pathway is not the sole mechanism responsible for sepsis induced apoptosis in the kidney. As a matter of fact, it has been found that also the intrinsic pathway is activated in endothelial and tubular cells exposed to LPS (Mariano et al., 2008; Cantaluppi et al., 2008). This mechanism involves the oligomerization of the pro-apoptotic members of the Bcl-2 family proteins, such as Bax, which translocates to the mitochondria and forms pores in 
the outer mitochondrial membrane that allow the release of cytochrome $C$ from the mitochondria. Cytosol cytochrome $\mathrm{C}$ binds to the adaptor protein apoptosis protease activating factor (APAF-1) and this complex binds to pro-caspase 9, forming the apoptosome. This in turn results in the auto-activation of caspase-9 (Mariano et al., 2008; Cantaluppi et al., 2008). One of the proposed mechanisms of protection induced by APC treatment in septic patients could also be due to its anti-apoptotic effects. Recent studies demonstrated that recombinant human APC directly modulates patterns of endothelial gene expression clustering into cell survival pathway and modulate several genes, including Bcl-2. Moreover, it normalizes $\mathrm{Bax} / \mathrm{Bcl}-2$ ratio and reduces caspase-3 signalling. Also the decrease in sepsis-AKI found in patients treated with the aggressive insulin therapy could be due by his powerful anti-apoptotic effect. Conversely, it has been demonstrated that high glucose concentration induces oxidative-stress-mediated apoptosis in tubular cells (Allen et al., 2003).

\subsubsection{Permeability molecules}

Proteinuria found in AKI patients is usually in the nephrotic range with a mixed glomerular and tubular pattern (Schiavon et al., 1988), suggesting a simultaneous defect of tubular reabsorption and an increase of glomerular permeability. Megalin is an endocytic receptor that regulates the physiological reabsorption of glomerular-filtered low molecular weight proteins (Christensen \& Birn, 2001). It has been shown that plasma derived from septic patients decreases the expression of megalin, suggesting that the impaired expression of this molecule may contribute to proteinuria resulting in a failure of tubular handling of filtered proteins (Mariano et al., 2008; Cantaluppi et al., 2008). Physiological tubular handling of electrolytes is based on the maintenance of cell polarity and on the integrity of tight junction protein expression (Lee et al., 2006). After challenge of tubular cells with septic plasmas, it has been observed a marked decrease of ZO-1 expression with a simultaneous alteration of trans-electrical resistance (TER) (Cantaluppi et al., 2008). These functional changes may alter the ability of tubular cells to maintain compositionally distinct fluid-filled compartments with precise electrolyte concentrations. Moreover, albumin diffusion across podocytes increases in the presence of septic plasma and this phenomenon is associated with decreased expression of nephrin, a slit diaphragm protein known to modulate glomerular permeability (Cantaluppi et al., 2008). Another molecule playing an important role in the correct organization and function of podocytes is nestin, able to stably link the intermediate filaments to other cytoskeleton proteins (Chen et al., 2006). The alterations in nephrin and cytoskeleton distribution may also account for the altered cell polarity and albumin transport across the podocyte monolayer observed after challenge with septic AKI plasma (Mariano et al., 2008; Cantaluppi et al., 2008).

\section{Cardiovascular}

\subsection{Pathophysiology}

The worsening of sepsis toward septic shock is characterized by hypotension refractory to fluid resuscitation. An important component of this process is the development of progressive cardiac and hemodynamic dysfunction. Traditionally, these disturbances have been described in a biphasic spectrum: early hyperdynamic shock characterized by increased cardiac output, decreased systemic vascular resistance (SVR) and warm, perfused skin, followed by cold hypodynamic shock, during which SVR increases to compensate for 
worsened cardiac output, resulting in tissue hypoperfusion, cool skin and eventual organ failure (Hoesel et al., 2007). However, it is now generally accepted that, after adequate volume resuscitation, patients develop a hyperdynamic circulatory state associated with high cardiac output, decreased systemic vascular resistance, and biventricular dilatation (Hunter \& Doddi, 2010). Experimental models of sepsis showed clear evidence of myocardial contractile disturbance both in vivo and in vitro. These disturbances are present even in early hyperdynamic shock, when aggressive volume replacement and adaptive left ventricular dilatation can combine to preserve cardiac output (Grocott-Mason \& Shah, 1998). What exactly triggers septic cardiomyopathy is still unknown. Cardiac dysfunction in sepsis is characterized by decreased contractility, impaired ventricular response to fluid therapy, and in some patients ventricular dilatation (Bouhemad et al., 2009). The hemodynamic instability is mainly due to dysfunction of vascular autoregulatory mechanisms in microcirculation and subsequently enhanced perfusion of large arteriovenous shunts (Matsuda \& Hattori, 2007).

\subsection{Major cell types involved}

The pathophysiology of cardiovascular dysfunction during sepsis involves a highly complex, integrated response that includes activation of number of cell types, inflammatory mediators and the hemostatic system. Central to this process is alterations in vascular endothelial, smooth muscle cells and cardiomyocyte function.

\subsection{Key molecular pathways and possible therapeutic targets \\ 6.3.1 Nitric oxide (NO)}

$\mathrm{NO}$ is produced by all types of cardiac and endothelial cells and has a multitude of cardiovascular effects both in healthy and disease states. Effects of NO relevant to sepsisinduced cardiovascular dysfunction include vasodilation, depression of mitochondrial respiration, and further release of pro-inflammatory cytokines (Massion et al., 2003). NO is produced from conversion of L-arginine to L-citrulline by nitric oxide synthase (NOS). In mammals, NOS has three isoforms: neuronal (nNOS/ NOS1), inducible (iNOS/ NOS2) and constitutive (cNOS/ NOS3). Current evidence suggests that early myocardial dysfunction in sepsis may occur through the over-production of $\mathrm{NO}$ and resultant cyclic guanosine monophosphate (cGMP) through cNOS activation in cardiac cells. Activation of iNOS and resultant nitric oxide may be more important in late sepsis-induced cardiovascular dysfunction. Peroxynitrite, a by-product of nitric oxide, has also been proposed as an important modulator of prolonged myocardial depression (Pacher et al., 2007). As a reflection of the complexity of the role of NO is in sepsis-induced myocardial depression, myocardial over-expression of cNOS has been shown to attenuate myocardial depression in sepsis models utilizing genetically modified mice (Fraccarollo et al., 2008). Unfortunately, initial attempts to block nitric oxide production as a therapeutic target have failed, likely due to vascular and other actions of NO in sepsis.

\subsubsection{Contractility pathway}

The concept of circulating myocardial depressant factors was first proposed by Parrillo et al. In this study the authors found myocardial depression in isolated myocytes exposed to serum obtained from septic patients with clinical manifestations of sepsis-induced myocardial dysfunction. Septic shock patients during the acute phase showed a significant 
lower extent of shortening compared with other patient groups including septic shock patients in the recovery phase (Parrillo et al., 1985). There was also a correlation between in vitro depression of contractility and in vivo myocardial depression measured by left ventricular ejection fraction. Further studies have identified cytokines such as TNF- $\alpha$, IL-1- $\beta$, and IL-6 as circulating causative factors of myocardial depression in sepsis. Lysozyme $c$ has been shown to have cardiac depressant actions in animal models of sepsis (Mink et al., 2008). Furthermore, competitive inhibition of lysozyme $c$ in these animal models was observed to be protective and prevented sepsis-induced myocardial dysfunction. Early studies suggest a potential role for endothelin-1 (ET-1) in the development of sepsis-induced myocardial depression (Konrad et al., 2004; Schuetz et al., 2007). Moreover calcium is thought to play an important role in the myocardial depression. Current evidence suggests that reductions in cytosolic calcium levels during sepsis lead to reduced contractility (Rudiger \& Singer, 2007). Calcium signalling and metabolism are linked to mitochondrial function, which is also altered in sepsis.

\section{Brain}

\subsection{Pathophysiology}

Several studies have demonstrated that sepsis survivors present long-term cognitive impairment, including alteration in memory, attention, concentration and/or global loss of cognitive function (Heyland et al., 2000; Hopkins et al., 1999; Hough \& Curtis, 2005). Most investigations have tried to understand the pathogenetic mechanisms of sepsis encephalopathy (SE) using animals or cell cultures (Jacob et al., 2011) due to obvious limitations in humans. Although these studies have expanded the understanding of central nervous system (CNS) cellular response to endotoxin or cytokines, the way in which these mechanisms relate to clinical brain injury remains obscure. It is important to note that the reciprocal interaction between the CNS and the immune response is considered one of the main components of the host response during sepsis. The brain mediates via the autonomic nervous system and neurohormones the growth and proliferation of most if not all tissues involved in immunity, and all immune cells have membrane or cytosolic receptors for a number of neuromediators. The systemic inflammatory response to infection results in brain activation, which subsequently generates an appropriate anti-inflammatory response. However, excess in pro-inflammatory mediators entering the brain can cause cerebral damage. In turn, dysfunction of the autonomic nervous and neuroendocrine systems may alter immunity in a vicious circle resulting in metabolic derangements and organ failure (Streck et al., 2008).

\subsection{Major cell types involved}

The anatomical substrate of the blood brain barrier (BBB) is the cerebral microvascular endothelium, which together with astrocytes, pericytes, neurons and the extracellular matrix, constitute a "neurovascular unit" that is essential for the health and function of the CNS. All the cell types forming the BBB are immunologically active and can be influenced by systemic inflammatory reactions and responses, such as those resulting from sepsis. Inflammatory mediators released by leukocytes in sepsis have profound effects on endothelial cells and astrocytes; damage to these cells results in impaired neuronal function. 


\subsection{Key molecular pathways and possible therapeutic targets \\ 7.3.1 Oxidative stress}

One important factor that can lead to cognitive impairment due to SE is oxidative stress. Studies on oxidative stress showed cerebral damage caused by active species of oxygen in some regions of the brain after sepsis induced by CLP. It has been demonstrated that, differently from other organs involved in septic response, CNS oxidative stress is restricted to earlier times after sepsis induction (Barichello et al., 2006). It has also been demonstrated an increase in superoxide dismutase activity without a proportional increase in catalase activity with a consequent increase in the relation of superoxide dismutase/catalase. Based on this evidence, the same authors also measured oxidative stress parameters in brains of rats after CLP and treated with antioxidants NAC (N-acetylcysteine) and/or DFX (deferoxamine) in the first hours after surgery. Ten and thirty days after CLP, behavior tests involving step down inhibitory avoidance, continuous multiple-trials step-down inhibitory avoidance and habituation to an open-field were conducted. It has been found that antioxidant treatment could significantly attenuate late cognitive deficits in sepsis survivors from CLP. In addition, the combined use of antioxidants attenuated oxidative damage in the hippocampus in early periods after sepsis induction. These results suggested a role of early CNS oxidative damage in the development of long-term cognitive deficits. In addition the authors demonstrated a new role to antioxidant treatment in an animal model of sepsis (Barichello et al., 2007).

\subsubsection{Inflammation}

Inflammation is being considered an important biological event that might increase the risk of major depressive episodes much like more traditional psychosocial factors. In this context, it is possible that pro-inflammatory cytokines, which are peripherally produced during the septic response, could contribute to the development of long-term cognitive dysfunction and behavioural symptoms related to sickness behaviour. When the activation of the peripheral immune system continues such as during systemic infections, the immune signalling to the brain may lead to an exacerbation of sickness and the development of symptoms of depression (Dantzer et al., 2008). Many studies suggest that these phenomena account for increased prevalence of clinical depression in critically ill people (Dantzer et al., 2008). Some studies also link pro-inflammatory cytokines and neuronal death. However, the mechanisms underlying pro-inflammatory cytokines and neuronal death are still poorly understood (Glass et al., 2010).

\subsubsection{Blood Brain Barrier (BBB)}

The BBB is established through specialized tight junctions of the endothelial cells, which are induced and maintained through interactions between astrocytes, pericytes and endothelial cells (Abbott et al., 2006). BBB dysfunction is found in patients and rodent models of sepsis and causes increased infiltration of inflammatory cells and increased exposure of the brain to toxins (Nishioku et al., 2009). The BBB impairment may be caused by disruption of the normal interaction between endothelial cells, astrocytes and pericytes leading to increased pineocytosis and disruption of tight junctions. Additionally, neuroinflammation with LPS exposure may also facilitate active directed transport of cytokines across the BBB (Nishioku et al., 2009). In sepsis, leukocytes are activated, adhere to the blood vessel and move into the tissue, a process mediated by adhesion molecules such as intercellular adhesion molecule (ICAM). The expression of ICAM is increased in septic encephalopathy, whereas platelet 
endothelial cell adhesion molecule (PECAM) remains unaltered (Hofer et al., 2008). One of the key inflammatory mediators is TNF- $\alpha$, which is also produced intrinsically in the brain where it regulates aquaporin 4 (AQP4) and alters transport of water into the brain resulting in edema (Alexander et al., 2008).

\subsubsection{Complement activation}

It has been shown that the complement cascade, especially C5a generated by complement activation, is an integral part of the central hub of the inflammatory response in sepsis (Rittirsch et al., 2008). It also induces apoptosis in the adrenomedullary cells, which are responsible for the bulk of endogenous catecholamines (Flierl et al., 2008). The cross talk between the complement cascade and coagulation, which is generally activated during sepsis, could further amplify complement activation in sepsis (Rittirsch et al., 2008). In addition to complement activation, glial activation induces the expression of Toll-like receptor 2 (TLR-2), IL-1 $\beta$, IL-6 and indoleamine 2, 3 dioxygenase (IDO) that could be prevented by the microglial inhibitor minocycline, modulating sickness (Henry et al., 2008). Both blocking C5a or its receptor, and inhibiting the alternative complement pathway, attenuates neuronal death in experimental traumatic brain injury (Sewell et al., 2004; Leinhase et al., 2007).

\section{Conclusion}

In summary, since MOF in the late stages of septic shock is the major contributor to patient death, further understanding of the cellular mechanisms involved in the development and progression of MOF is imperative to identify novel treatment strategies.

\section{Acknowledgements}

The authors would like to thank their colleagues, E. Tonoli, G. Muraca and F. Civiletti for assistance in researching, modifying and discussing various sections of this chapter, and Prof. V.M. Ranieri for his continued support.

\section{References}

Vincent JL, Taccone F, Schmit X. Classification, incidence, and outcomes of sepsis and multiple organ failure. Contrib Nephrol 2007;156:64-74.

Legrand M, Klijn E, Payen D, Ince C. The response of the host microcirculation to bacterial sepsis: does the pathogen matter? J Mol Med 2010;88:127-133.

Salomao R, Martins PS, Brunialti MK, Fernandes ML, Martos LS, Mendes ME, Gomes NE, Rigato O. TLR signaling pathway in patients with sepsis. Shock 2008;30 Suppl 1:7377.

Baumgarten G, Knuefermann P, Wrigge H, Putensen C, Stapel H, Fink K, Meyer R, Hoeft A, Grohe C. Role of Toll-like receptor 4 for the pathogenesis of acute lung injury in Gram-negative sepsis. Eur J Anaesthesiol 2006;23:1041-1048.

Rittirsch D, Flierl MA, Ward PA. Harmful molecular mechanisms in sepsis. Nat Rev Immunol 2008;8:776-787. 
Cunningham PN, Wang Y, Guo R, He G, Quigg RJ. Role of Toll-like receptor 4 in endotoxininduced acute renal failure. J Immunol 2004;172:2629-2635.

Bellingan GJ. The pathogenesis of ALI/ARDS. Thorax 2002;57:540-546.

Ware LB, Matthay MA. The acute respiratory distress syndrome. N Engl J Med 2000;342:1334-1349.

Abraham E, Singer M. Mechanisms of sepsis-induced organ dysfunction. Crit Care Med 2007;35:2408-2416.

Bhatia M, Moochhala S. Role of inflammatory mediators in the pathophysiology of acute respiratory distress syndrome. J Pathol 2004;202:145-156.

Marshall JC. Inflammation, coagulopathy, and the pathogenesis of multiple organ dysfunction syndrome. Crit Care Med 2001;29:S99-106.

Vlahakis NE, Hubmayr RD. Cellular stress failure in ventilator-injured lungs. Am J Respir Crit Care Med 2005;171:1328-1342.

Agnese DM, Calvano JE, Hahm SJ, Coyle SM, Corbett SA, Calvano SE, Lowry SF. Human toll-like receptor 4 mutations but not CD14 polymorphisms are associated with an increased risk of gram-negative infections. J Infect Dis 2002;186:1522-1525.

Lorenz E, Mira JP, Frees KL, Schwartz DA. Relevance of mutations in the TLR4 receptor in patients with gram-negative septic shock. Arch Intern Med 2002;162:10281032.

Yang KY, Arcaroli JJ, Abraham E. Early alterations in neutrophil activation are associated with outcome in acute lung injury. Am J Respir Crit Care Med 2003;167:15671574.

Bohrer H, Qiu F, Zimmermann T, Zhang Y, Jllmer T, Mannel D, Bottiger BW, Stern DM, Waldherr R, Saeger HD, Ziegler R, Bierhaus A, Martin E, Nawroth PP. Role of NFkappaB in the mortality of sepsis. J Clin Invest 1997;100:972-985.

Pellegrini JD, Puyana JC, Lapchak PH, Kodys K, Miller-Graziano CL. A membrane TNFalpha/TNFR ratio correlates to MODS score and mortality. Shock 1996;6:389396.

Stuber F, Petersen M, Bokelmann F, Schade U. A genomic polymorphism within the tumor necrosis factor locus influences plasma tumor necrosis factor-alpha concentrations and outcome of patients with severe sepsis. Crit Care Med 1996;24:381-384.

Bozza FA, Salluh JI, Japiassu AM, Soares M, Assis EF, Gomes RN, Bozza MT, Castro-FariaNeto HC, Bozza PT. Cytokine profiles as markers of disease severity in sepsis: a multiplex analysis. Crit Care 2007;11:R49.

Creagh-Brown BC, Quinlan GJ, Evans TW, Burke-Gaffney A. The RAGE axis in systemic inflammation, acute lung injury and myocardial dysfunction: an important therapeutic target? Intensive Care Med 2010;36:1644-1656.

Buckley ST, Ehrhardt C. The receptor for advanced glycation end products (RAGE) and the lung. J Biomed Biotechnol 2010;2010:917108.

Schmidt AM, Yan SD, Yan SF, Stern DM. The biology of the receptor for advanced glycation end products and its ligands. Biochim Biophys Acta 2000;1498:99-111.

Lutterloh EC, Opal SM, Pittman DD, Keith JC, Jr., Tan XY, Clancy BM, Palmer H, Milarski K, Sun Y, Palardy JE, Parejo NA, Kessimian N. Inhibition of the RAGE products increases survival in experimental models of severe sepsis and systemic infection. Crit Care 2007;11:R122. 
Sawa H, Ueda T, Takeyama Y, Yasuda T, Shinzeki M, Nakajima T, Kuroda Y. Blockade of high mobility group box-1 protein attenuates experimental severe acute pancreatitis. World J Gastroenterol 2006;12:7666-7670.

Yang ZY, Ling Y, Yin T, Tao J, Xiong JX, Wu HS, Wang CY. Delayed ethyl pyruvate therapy attenuates experimental severe acute pancreatitis via reduced serum high mobility group box 1 levels in rats. World J Gastroenterol 2008;14:4546-4550.

Calfee CS, Ware LB, Eisner MD, Parsons PE, Thompson BT, Wickersham N, Matthay MA. Plasma receptor for advanced glycation end products and clinical outcomes in acute lung injury. Thorax 2008;63:1083-1089.

Uchida T, Shirasawa M, Ware LB, Kojima K, Hata Y, Makita K, Mednick G, Matthay ZA, Matthay MA. Receptor for advanced glycation end-products is a marker of type I cell injury in acute lung injury. Am J Respir Crit Care Med 2006;173:10081015.

Yum HK, Arcaroli J, Kupfner J, Shenkar R, Penninger JM, Sasaki T, Yang KY, Park JS, Abraham E. Involvement of phosphoinositide 3-kinases in neutrophil activation and the development of acute lung injury. J Immunol 2001;167:66016608.

Ong E, Gao XP, Predescu D, Broman M, Malik AB. Role of phosphatidylinositol 3-kinase-gamma in mediating lung neutrophil sequestration and vascular injury induced by E. coli sepsis. Am J Physiol Lung Cell Mol Physiol 2005;289:L1094L1103.

Martin EL, Souza DG, Fagundes CT, Amaral FA, Assenzio B, Puntorieri V, Del Sorbo L, Fanelli V, Bosco M, Delsedime L, Pinho JF, Lemos VS, Souto FO, Alves-Filho JC, Cunha FQ, Slutsky AS, Ruckle T, Hirsch E, Teixeira MM, Ranieri VM. PI3K\{gamma\} Kinase Activity Contributes to Sepsis and Organ Damage by Altering Neutrophil Recruitment. Am J Respir Crit Care Med 2010.

Martin EL, Ranieri VM. Phosphorylation mechanisms in intensive care medicine. Intensive Care Med 2011;37:7-18.

Wheeler DS. Death to sepsis: targeting apoptosis pathways in sepsis. Crit Care 2009;13: 1010.

Chopra M, Reuben JS, Sharma AC. Acute lung injury:apoptosis and signaling mechanisms. Exp Biol Med (Maywood) 2009;234:361-371.

Albertine KH, Soulier MF, Wang Z, Ishizaka A, Hashimoto S, Zimmerman GA, Matthay MA, Ware LB. Fas and fas ligand are up-regulated in pulmonary edema fluid and lung tissue of patients with acute lung injury and the acute respiratory distress syndrome. Am J Pathol 2002;161:1783-1796.

Matute-Bello G, Liles WC, Steinberg KP, Kiener PA, Mongovin S, Chi EY, Jonas M, Martin TR. Soluble Fas ligand induces epithelial cell apoptosis in humans with acute lung injury (ARDS). J Immunol 1999;163:2217-2225.

Neff TA, Guo RF, Neff SB, Sarma JV, Speyer CL, Gao H, Bernacki KD, Huber-Lang M, McGuire S, Hoesel LM, Riedemann NC, Beck-Schimmer B, Zetoune FS, Ward PA. Relationship of acute lung inflammatory injury to Fas/FasL system. Am J Pathol 2005;166:685-694. 
Perl M, Chung CS, Perl U, Lomas-Neira J, de Paepe M, Cioffi WG, Ayala A. Fas-induced pulmonary apoptosis and inflammation during indirect acute lung injury. Am J Respir Crit Care Med 2007;176:591-601.

Matsuda N, Yamamoto S, Takano K, Kageyama S, Kurobe Y, Yoshihara Y, Takano Y, Hattori Y. Silencing of fas-associated death domain protects mice from septic lung inflammation and apoptosis. Am J Respir Crit Care Med 2009;179:806815.

Perl M, Chung CS, Lomas-Neira J, Rachel TM, Biffl WL, Cioffi WG, Ayala A. Silencing of Fas, but not caspase-8, in lung epithelial cells ameliorates pulmonary apoptosis, inflammation, and neutrophil influx after hemorrhagic shock and sepsis. Am J Pathol 2005;167:1545-1559.

Bernard GR, Vincent JL, Laterre PF, LaRosa SP, Dhainaut JF, Lopez-Rodriguez A, Steingrub JS, Garber GE, Helterbrand JD, Ely EW, Fisher CJ, Jr. Efficacy and safety of recombinant human activated protein $\mathrm{C}$ for severe sepsis. $\mathrm{N}$ Engl J Med 2001;344:699-709.

Shorr AF, Bernard GR, Dhainaut JF, Russell JR, Macias WL, Nelson DR, Sundin DP. Protein $\mathrm{C}$ concentrations in severe sepsis: an early directional change in plasma levels predicts outcome. Crit Care 2006;10:R92.

Matthay MA, Ware LB. Plasma protein C levels in patients with acute lung injury: prognostic significance. Crit Care Med 2004;32:S229-S232.

Waerhaug K, Kuklin VN, Kirov MY, Sovershaev MA, Langbakk B, Ingebretsen OC, Ytrehus $\mathrm{K}$, Bjertnaes LJ. Recombinant human activated protein $\mathrm{C}$ attenuates endotoxininduced lung injury in awake sheep. Crit Care 2008;12:R104.

Wang Z, Su F, Rogiers P, Vincent JL. Beneficial effects of recombinant human activated protein C in a ewe model of septic shock Crit Care Med 2007;35:2594-2600.

Sarangi PP, Lee HW, Kim M. Activated protein C action in inflammation. Br J Haematol 2010;148:817-833.

Mosnier LO, Zlokovic BV, Griffin JH. The cytoprotective protein C pathway. Blood 2007;109:3161-3172.

Jean-Baptiste E. Cellular mechanisms in sepsis. J Intensive Care Med 2007;22:63-72.

Van Amersfoort ES, Van Berkel TJ, Kuiper J. Receptors, mediators, and mechanisms involved in bacterial sepsis and septic shock. Clin Microbiol Rev 2003;16:379-414.

Yang S, Zhou M, Chaudry IH, Wang P. Norepinephrine-induced hepatocellular dysfunction in early sepsis is mediated by activation of alpha2-adrenoceptors. Am J Physiol Gastrointest Liver Physiol 2001;281:G1014-G1021.

Dhainaut JF, Marin N, Mignon A, Vinsonneau C. Hepatic response to sepsis: interaction between coagulation and inflammatory processes. Crit Care Med 2001;29:S42-S47.

Mookerjee RP. Acute-on-chronic liver failure: the liver and portal haemodynamics. Curr Opin Crit Care 2011;17:170-176.

Cheluvappa R, Denning GM, Lau GW, Grimm MC, Hilmer SN, Le Couteur DG. Pathogenesis of the hyperlipidemia of Gram-negative bacterial sepsis may involve pathomorphological changes in liver sinusoidal endothelial cells. Int J Infect Dis 2010;14:e857-e867.

Yang QH, Liu DW, Wang XT, Yang RL, Shi Y, Long Y, Liu HZ, He HW, Zhou X, Tang B. G1 cell cycle arrest signaling in hepatic injury after intraperitoneal sepsis in rats. Inflamm Res 2011. 
Fong YM, Marano MA, Moldawer LL, Wei H, Calvano SE, Kenney JS, Allison AC, Cerami A, Shires GT, Lowry SF. The acute splanchnic and peripheral tissue metabolic response to endotoxin in humans. J Clin Invest 1990;85:1896-1904.

Ananian P, Hardwigsen J, Bernard D, Le Treut YP. Serum acute-phase protein level as indicator for liver failure after liver resection. Hepatogastroenterology 2005;52:857861.

Bevilacqua MP, Pober JS, Majeau GR, Fiers W, Cotran RS, Gimbrone MA, Jr. Recombinant tumor necrosis factor induces procoagulant activity in cultured human vascular endothelium: characterization and comparison with the actions of interleukin 1. Proc Natl Acad Sci U S A 1986;83:4533-4537.

Zhang P, Xie M, Spitzer JA. Hepatic neutrophil sequestration in early sepsis: enhanced expression of adhesion molecules and phagocytic activity. Shock 1994;2:133-140.

Malmros C, Holst E, Hansson L, Martensson L, Thorne J. Dynamic accumulation of neutrophils in lungs and visceral organs during early abdominal sepsis in the pig. World J Surg 1994;18:811-816.

Holman JM, Jr., Saba TM. Hepatocyte injury during post-operative sepsis: activated neutrophils as potential mediators. J Leukoc Biol 1988;43:193-203.

Stearns-Kurosawa DJ, Osuchowski MF, Valentine C, Kurosawa S, Remick DG. The pathogenesis of sepsis. Annu Rev Pathol 2011;6:19-48.

Asaka S, Shibayama Y, Nakata K. Pathogenesis of focal and random hepatocellular necrosis in endotoxemia: microscopic observation in vivo. Liver 1996;16:183-187.

Jagneaux T, Taylor DE, Kantrow SP. Coagulation in sepsis. Am J Med Sci 2004;328:196-204.

Nitescu N, Grimberg E, Ricksten SE, Marcussen N, Nordlinder H, Guron G. Effects of thrombin inhibition with melagatran on renal hemodynamics and function and liver integrity during early endotoxemia. Am J Physiol Regul Integr Comp Physiol 2007;292:R1117-R1124.

Inthorn D, Hoffmann JN, Hartl WH, Muhlbayer D, Jochum M. Antithrombin III supplementation in severe sepsis: beneficial effects on organ dysfunction. Shock 1997;8:328-334.

Wiedermann CJ, Hoffmann JN, Juers M, Ostermann H, Kienast J, Briegel J, Strauss R, Keinecke HO, Warren BL, Opal SM. High-dose antithrombin III in the treatment of severe sepsis in patients with a high risk of death: efficacy and safety. Crit Care Med 2006;34:285-292.

Xu J, Zhang X, Pelayo R, Monestier M, Ammollo CT, Semeraro F, Taylor FB, Esmon NL, Lupu F, Esmon CT. Extracellular histones are major mediators of death in sepsis. Nat Med 2009;15:1318-1321.

Rinaldi L, Marietta M, Mignini MA, Donno L, Busani S, Codeluppi M, Masetti M, Girardis M. Use of activated protein $C$ in liver transplantation patients with septic shock. Liver Transpl 2008;14:1598-1602.

Huynh T, Nguyen N, Keller S, Moore C, Shin MC, McKillop IH. Reducing leukocyte trafficking preserves hepatic function after sepsis. J Trauma 2010;69:360-367.

Ward PA, Gao H. Sepsis, complement and the dysregulated inflammatory response. J Cell Mol Med 2009;13:4154-4160.

Guo RF, Ward PA. C5a, a therapeutic target in sepsis. Recent Pat Antiinfect Drug Discov 2006;1:57-65. 
Riedemann NC, Guo RF, Neff TA, Laudes IJ, Keller KA, Sarma VJ, Markiewski MM, Mastellos D, Strey CW, Pierson CL, Lambris JD, Zetoune FS, Ward PA. Increased C5a receptor expression in sepsis. J Clin Invest 2002;110:101-108.

Lafrance JP, Miller DR. Acute kidney injury associates with increased long-term mortality. J Am Soc Nephrol 2010;21:345-352.

Uchino S, Kellum JA, Bellomo R, Doig GS, Morimatsu H, Morgera S, Schetz M, Tan I, Bouman C, Macedo E, Gibney N, Tolwani A, Ronco C. Acute renal failure in critically ill patients: a multinational, multicenter study. JAMA 2005;294:813-818.

Silvester W, Bellomo R, Cole L. Epidemiology, management, and outcome of severe acute renal failure of critical illness in Australia. Crit Care Med 2001;29:1910-1915.

Wan L, Bagshaw SM, Langenberg C, Saotome T, May C, Bellomo R. Pathophysiology of septic acute kidney injury: what do we really know? Crit Care Med 2008;36:S198S203.

Langenberg C, Wan L, Egi M, May CN, Bellomo R. Renal blood flow and function during recovery from experimental septic acute kidney injury. Intensive Care Med 2007;33:1614-1618.

Bagshaw SM, Langenberg C, Wan L, May CN, Bellomo R. A systematic review of urinary findings in experimental septic acute renal failure. Crit Care Med 2007;35:15921598.

Licari E, Calzavacca P, Ronco C, Bellomo R. Fluid resuscitation and the septic kidney: the evidence. Contrib Nephrol 2007;156:167-177.

Bradley VE, Shier MR, Lucas CE, Rosenberg IK. Renal hemodynamic response to furosemide in septic and injured patients. Surgery 1976;79:549-554.

Humphrey TJ, Baskerville A, Chart H, Rowe B, Whitehead A. Salmonella enteritidis PT4 infection in specific pathogen free hens: influence of infecting dose. Vet Rec 1991;129:482-485.

Jo SK, Cha DR, Cho WY, Kim HK, Chang KH, Yun SY, Won NH. Inflammatory cytokines and lipopolysaccharide induce Fas-mediated apoptosis in renal tubular cells. Nephron 2002;91:406-415.

Guo R, Wang Y, Minto AW, Quigg RJ, Cunningham PN. Acute renal failure in endotoxemia is dependent on caspase activation. J Am Soc Nephrol 2004;15:3093-3102.

Cantaluppi V, Assenzio B, Pasero D, Romanazzi GM, Pacitti A, Lanfranco G, Puntorieri V, Martin EL, Mascia L, Monti G, Casella G, Segoloni GP, Camussi G, Ranieri VM. Polymyxin-B hemoperfusion inactivates circulating proapoptotic factors. Intensive Care Med 2008;34:1638-1645.

Mariano F, Cantaluppi V, Stella M, Romanazzi GM, Assenzio B, Cairo M, Biancone L, Triolo G, Ranieri VM, Camussi G. Circulating plasma factors induce tubular and glomerular alterations in septic burns patients. Crit Care 2008;12:R42.

Allen DA, Harwood S, Varagunam M, Raftery MJ, Yaqoob MM. High glucose-induced oxidative stress causes apoptosis in proximal tubular epithelial cells and is mediated by multiple caspases. FASEB J 2003;17:908-910.

Schiavon M, Di Landro D, Baldo M, De Silvestro G, Chiarelli A. A study of renal damage in seriously burned patients. Burns Incl Therm Inj 1988;14:107-112.

Christensen EI, Birn H. Megalin and cubilin: synergistic endocytic receptors in renal proximal tubule. Am J Physiol Renal Physiol 2001;280:F562-F573. 
Lee DB, Huang E, Ward HJ. Tight junction biology and kidney dysfunction. Am J Physiol Renal Physiol 2006;290:F20-F34.

Chen J, Boyle S, Zhao M, Su W, Takahashi K, Davis L, Decaestecker M, Takahashi T, Breyer MD, Hao CM. Differential expression of the intermediate filament protein nestin during renal development and its localization in adult podocytes. J Am Soc Nephrol 2006;17:1283-1291.

Hoesel LM, Niederbichler AD, Ward PA. Complement-related molecular events in sepsis leading to heart failure. Mol Immunol 2007;44:95-102.

Hunter JD, Doddi M. Sepsis and the heart. Br J Anaesth 2010;104:3-11.

Grocott-Mason RM, Shah AM. Cardiac dysfunction in sepsis: new theories and clinical implications. Intensive Care Med 1998;24:286-295.

Bouhemad B, Nicolas-Robin A, Arbelot C, Arthaud M, Feger F, Rouby JJ. Acute left ventricular dilatation and shock-induced myocardial dysfunction. Crit Care Med 2009;37:441-447.

Matsuda N, Hattori Y. Vascular biology in sepsis: pathophysiological and therapeutic significance of vascular dysfunction. J Smooth Muscle Res 2007;43:117-137.

Massion PB, Feron O, Dessy C, Balligand JL. Nitric oxide and cardiac function: ten years after, and continuing. Circ Res 2003;93:388-398.

Pacher P, Beckman JS, Liaudet L. Nitric oxide and peroxynitrite in health and disease. Physiol Rev 2007;87:315-424.

Fraccarollo D, Widder JD, Galuppo P, Thum T, Tsikas D, Hoffmann M, Ruetten H, Ertl G, Bauersachs J. Improvement in left ventricular remodeling by the endothelial nitric oxide synthase enhancer AVE9488 after experimental myocardial infarction. Circulation 2008;118:818-827.

Parrillo JE, Burch C, Shelhamer JH, Parker MM, Natanson C, Schuette W. A circulating myocardial depressant substance in humans with septic shock. Septic shock patients with a reduced ejection fraction have a circulating factor that depresses in vitro myocardial cell performance. J Clin Invest 1985;76:1539-1553.

Mink SN, Kasian K, Jacobs H, Cheng ZQ, Light RB. N,N'-diacetylchitobiose, an inhibitor of lysozyme, reverses myocardial depression and lessens norepinephrine requirements in Escherichia coli sepsis in dogs. Shock 2008;29:681-687.

Konrad D, Oldner A, Rossi P, Wanecek M, Rudehill A, Weitzberg E. Differentiated and dose-related cardiovascular effects of a dual endothelin receptor antagonist in endotoxin shock. Crit Care Med 2004;32:1192-1199.

Schuetz P, Christ-Crain M, Morgenthaler NG, Struck J, Bergmann A, Muller B. Circulating precursor levels of endothelin-1 and adrenomedullin, two endothelium-derived, counteracting substances, in sepsis. Endothelium 2007;14:345-351.

Rudiger A, Singer M. Mechanisms of sepsis-induced cardiac dysfunction. Crit Care Med 2007;35:1599-1608.

Heyland DK, Hopman W, Coo H, Tranmer J, McColl MA. Long-term health-related quality of life in survivors of sepsis. Short Form 36: a valid and reliable measure of healthrelated quality of life. Crit Care Med 2000;28:3599-3605.

Hopkins RO, Weaver LK, Pope D, Orme JF, Bigler ED, Larson-LOHR V. Neuropsychological sequelae and impaired health status in survivors of severe acute respiratory distress syndrome. Am J Respir Crit Care Med 1999;160:50-56. 
Hough CL, Curtis JR. Long-term sequelae of critical illness: memories and health-related quality of life. Crit Care 2005;9:145-146.

Jacob A, Brorson JR, Alexander JJ. Septic encephalopathy: inflammation in man and mouse. Neurochem Int 2011;58:472-476.

Streck EL, Comim CM, Barichello T, Quevedo J. The septic brain. Neurochem Res 2008;33:2171-2177.

Barichello T, Fortunato JJ, Vitali AM, Feier G, Reinke A, Moreira JC, Quevedo J, Dal Pizzol F. Oxidative variables in the rat brain after sepsis induced by cecal ligation and perforation. Crit Care Med 2006;34:886-889.

Barichello T, Machado RA, Constantino L, Valvassori SS, Reus GZ, Martins MR, Petronilho F, Ritter C, Quevedo J, Dal Pizzol F. Antioxidant treatment prevented late memory impairment in an animal model of sepsis. Crit Care Med 2007;35:2186-2190.

Dantzer R, O'Connor JC, Freund GG, Johnson RW, Kelley KW. From inflammation to sickness and depression: when the immune system subjugates the brain. Nat Rev Neurosci 2008;9:46-56.

Glass CK, Saijo K, Winner B, Marchetto MC, Gage FH. Mechanisms underlying inflammation in neurodegeneration. Cell 2010;140:918-934.

Abbott NJ, Ronnback L, Hansson E. Astrocyte-endothelial interactions at the blood-brain barrier. Nat Rev Neurosci 2006;7:41-53.

Nishioku T, Dohgu S, Takata F, Eto T, Ishikawa N, Kodama KB, Nakagawa S, Yamauchi A, Kataoka Y. Detachment of brain pericytes from the basal lamina is involved in disruption of the blood-brain barrier caused by lipopolysaccharide-induced sepsis in mice. Cell Mol Neurobiol 2009;29:309-316.

Hofer S, Bopp C, Hoerner C, Plaschke K, Faden RM, Martin E, Bardenheuer HJ, Weigand MA. Injury of the blood brain barrier and up-regulation of icam-1 in polymicrobial sepsis. J Surg Res 2008;146:276-281.

Alexander JJ, Jacob A, Cunningham P, Hensley L, Quigg RJ. TNF is a key mediator of septic encephalopathy acting through its receptor, TNF receptor-1. Neurochem Int 2008;52:447-456.

Flierl MA, Rittirsch D, Chen AJ, Nadeau BA, Day DE, Sarma JV, Huber-Lang MS, Ward PA. The complement anaphylatoxin C5a induces apoptosis in adrenomedullary cells during experimental sepsis. PLoS One 2008;3:e2560.

Henry CJ, Huang Y, Wynne A, Hanke M, Himler J, Bailey MT, Sheridan JF, Godbout JP. Minocycline attenuates lipopolysaccharide (LPS)-induced neuroinflammation, sickness behavior, and anhedonia. J Neuroinflammation 2008;5:15.

Sewell DL, Nacewicz B, Liu F, Macvilay S, Erdei A, Lambris JD, Sandor M, Fabry Z. Complement $\mathrm{C} 3$ and $\mathrm{C} 5$ play critical roles in traumatic brain cryoinjury: blocking effects on neutrophil extravasation by C5a receptor antagonist. J Neuroimmunol 2004;155:55-63.

Leinhase I, Rozanski M, Harhausen D, Thurman JM, Schmidt OI, Hossini AM, Taha ME, Rittirsch D, Ward PA, Holers VM, Ertel W, Stahel PF. Inhibition of the alternative complement activation pathway in traumatic brain injury by a monoclonal antifactor B antibody: a randomized placebo-controlled study in mice. J Neuroinflammation 2007;4:13. 


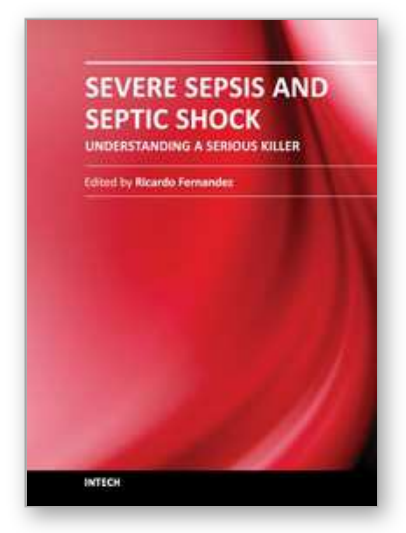

\author{
Severe Sepsis and Septic Shock - Understanding a Serious Killer \\ Edited by Dr Ricardo Fernandez
}

ISBN 978-953-307-950-9

Hard cover, 436 pages

Publisher InTech

Published online 10, February, 2012

Published in print edition February, 2012

Despite recent advances in the management of severe sepsis and septic shock, this condition continues to be the leading cause of death worldwide. Some experts usually consider sepsis as one of the most challenging syndromes because of its multiple presentations and the variety of its complications. Various investigators from all over the world got their chance in this book to provide important information regarding this deadly disease. We hope that the efforts of these investigators will result in a useful way to continue with intense work and interest for the care of our patients.

\title{
How to reference
}

In order to correctly reference this scholarly work, feel free to copy and paste the following:

Barbara Assenzio and Erica L. Martin-Conte (2012). Cellular Mechanisms of MOF During Severe Sepsis and Septic Shock, Severe Sepsis and Septic Shock - Understanding a Serious Killer, Dr Ricardo Fernandez (Ed.), ISBN: 978-953-307-950-9, InTech, Available from: http://www.intechopen.com/books/severe-sepsis-andseptic-shock-understanding-a-serious-killer/cellular-mechanisms-of-mof-during-septic-shock

\section{INTECH}

open science | open minds

\section{InTech Europe}

University Campus STeP Ri

Slavka Krautzeka 83/A

51000 Rijeka, Croatia

Phone: +385 (51) 770447

Fax: +385 (51) 686166

www.intechopen.com

\section{InTech China}

Unit 405, Office Block, Hotel Equatorial Shanghai

No.65, Yan An Road (West), Shanghai, 200040, China

中国上海市延安西路65号上海国际贵都大饭店办公楼 405 单元

Phone: +86-21-62489820

Fax: +86-21-62489821 
(C) 2012 The Author(s). Licensee IntechOpen. This is an open access article distributed under the terms of the Creative Commons Attribution 3.0 License, which permits unrestricted use, distribution, and reproduction in any medium, provided the original work is properly cited. 